\title{
Process Capability Analysis of a Centre Lathe Turning Process
}

\author{
Andrew A. Erameh"1, Nurudeen A. Raji ${ }^{2}$, Rasheed 0. Durojaye ${ }^{3}$, Abiodun A. Yussouff ${ }^{4}$ \\ ${ }^{1}$ Department of Mechanical Engineering, Igbinedion University, Okada, Nigeria \\ ${ }^{2}$ Department of Mechanical Engineering, Lagos State University, Ojo, Nigeria \\ ${ }^{3}$ Department of Structures and Aerodynamics, National Space Research and Development Agency, Lagos, Nigeria \\ ${ }^{4}$ Department of Computer Engineering, Grace Polytechnic, Omu, Nigeria \\ Email:kunle_raji@yahoo.com
}

Received 14 December 2015; accepted 12 March 2016; published 15 March 2016

Copyright (C) 2016 by authors and Scientific Research Publishing Inc.

This work is licensed under the Creative Commons Attribution International License (CC BY).

http://creativecommons.org/licenses/by/4.0/

(c) (†) Open Access

\begin{abstract}
A process capability study is performed for the turning process on a general purpose center lathe in order to verify the process performance and machine ability to perform within specified tolerance limit. The process and machine capability indices were measured to determine the process and machine adequacy for industrial application. The tolerance limits were obtained from the given nominal size of the shaft, using the basic hole system and 90 sample shafts were turned on the lathe machine to specification for varying spindle speed and feed rate of the lathe. Three (3) samples were randomly selected for the turning process of a combination of the spindle speed and feed rate as a subgroup size for a total subgroup of thirty (30). The diameters (representing the quality characteristics) were used to generate control charts and capability histogram for the process. The process is within statistical control but found incapable of meeting up to specification because the capability index $\left(C_{p}\right)$ measured was less than 1 and the machine capability for industrial application is not adequate.
\end{abstract}

\section{Keywords}

Center Lathe, Specification, Control Chart, Range, Shaft, Basic Hole System, Process Capability, Turning Process

\section{Introduction}

Machining is a general purpose manufacturing process for the manufacture of machine components and the performance evaluation of metal cutting machine tools is often based on their capability in machining work piece to specified details. The ISO standards had described the statistical methods of managing the machining process of 
sample work piece on machine tools. Process capability is the long-term performance level of a process brought under statistical control. Statistical process control is an excellent quality assurance tool to improve the quality of manufacture and ultimately scores on end-customer satisfaction [1]. The process capability is the ability of the combination of the equipment to produce a product that will consistently meet the design requirements and the customer expectation. The analysis ensures that processes are fit for industrial specification and limiting the process variation is important in achieving product quality characteristics [2]. A computational framework for control of machining system capability was discussed in [3]. Process capability indices are effective tools for the continuous improvement of quality, productivity and managerial decisions [4]. The indices form complementary system of measurement of process performance. The turning operation process capability indices could be evaluated towards measuring the performance of the process. The capability indices could be used to compare controlled process output to the specification limit desired [5] [6]. Process capability studies indicate if a process is capable of producing virtually all-conforming product.

Process capability indices performance measure of the machine operation has become very popular in assessing the capability of manufacturing processes hence determining the machine tool performance. More and more efforts have been devoted to studies and applications of process capability indices. A process capability index is a numerical summary that compares the behavior of a product or process characteristic to engineering specifications [7] [8]. These measures are also often called capability or performance indices or ratios; we use capability index as the generic term. A capability index relates the voice of the customer (specification limits) to the voice of the process. A large value of the index indicates that the current process is capable of producing parts that, in all likelihood, will meet or exceed the customer's requirements. A capability index is convenient because it reduces complex information about the process to a single number. Capability indices have several applications, though the use of the indices is driven mostly by monitoring requirements specified by customers. Many customers ask their suppliers to record capability indices for all special product characteristics on a regular basis. The indices are used to communicate how well the process has performed. For stable or predictable processes, it is assumed that these indices also indicate expected future performance. Suppliers may also use capability indices for different characteristics to establish priorities for improvement activities. Similarly, the effect of a process change can be assessed by comparing capability indices calculated before and after the change. Designers had to deal with this by specifying tolerances, which are allowable variation from the normal values. Conceptual tolerance limits are designed requirements while the control limit depends on how the process actually operates. Process capability allows one to quantify by how well a process can produce acceptable product. The importance of tolerance and the control of manufacturing variation received increased strive to improve productivity and in the quality of the products. There is a realization that it is no longer acceptable to arbitrarily select the tolerances in engineering drawings, as the effects of tolerance assignment are better tolerated. The variation constrained or bounded by the tolerances also directly affect product performance and robustness of the design and poorly performing products will eventually lose their place in the market. The possibility of minimizing failure cost of electronic production processes by adjusting acceptance limits of such resulting product of the operation was analysed through simulation in [9].

The concept of the influence of the process parameters had also been focused [10]-[12]. [10] revealed that the influence of the machine feed, diameter of the workpiece, and diameter of the hole being bored on in a machining operation significantly influenced the tool wear rate. The effect of the machining parameter on the tool life for machining process was investigated by [13] where the spindle speed was found to have an inverse influence on tool life and was more dominant than the effect of feed rate. [10] showed that the combined effect of cutting speed at it's lower level, feed rate and depth of cut at their higher values, and larger work piece diameter can result into increasing chip microhardness during formation in machining. [11] attempt to study the effect of machining parameters on the surface characteristics and quality of machined part with respect to the specific cutting pressure, microstructural alteration and microhardness of high speed dry turning of superalloy Inconel 718. Specific cutting pressure were discussed to have affected the machining process and tool capability. The effects cutting speed and feed rate on main cutting force and surface roughness were experimentally investigated by [14] in which optimal and critical cutting parameters were determined. Cutting speed limit was determined to avoid formation of built up edge and layer during machining of AA6351 (T6) alloy with uncoated carbide inserts. The results of their study showed that the feed rate considerably affect the main cutting force and surface roughness of the product. In the investigation by [15], the surface roughness of a machined piece tends to decrease with increasing cutting speed during turning operation up to a specified limit while the roughness decreases with de- 
creasing feed rate of the machine tool. Turning tests performed on nickel-based alloy show that the cutting speed during turning of the material had significant influence on the surface roughness and chip formation [16].

The ability to predict the accuracy of machine parts in a machining operation could provide possibility of obtaining optimal machining process and the ability to design a robust optimal performing machining system [17].

The focus of this study is to investigate the process capability of turning on the general purpose AJL180325VS Gap Bed Lathes machine installed for student training for purpose of industrial application. The machine was investigated to determine its suitability for machining operation at specified tolerance limit as may be required by the industrial clients.

\section{Experimental Procedure}

The experimental procedure includes the selection of the specific materials, machine and the machining operation required for the capability study.

\subsection{Materials}

The work materials used for the study was the annealed cold drawn SAE 1050 high carbon steel material of 50 $\mathrm{mm}$ diameter cut to length of $300 \mathrm{~mm}$ for each work piece. The typical properties of the steel include the elastic modulus of $210 \mathrm{GPa}$, tensile strength of $636 \mathrm{MPa}$, yield strength of 369.4 MPa, hardness of $187 \mathrm{HB}$ with impact strength of $16.9 \mathrm{~J}$ annealed at $790^{\circ} \mathrm{C}$. The general purpose AJL180-325VS Gap Bed Lathes machine of $300 \mathrm{~mm}$ turning length capacity installed with $250 \mathrm{~mm}$ chuck diameter was used with a High Speed Steel (HSS) single point cutting tool of $5^{\circ}$ rake angle and $8^{\circ}$ relief angle with nose radius of $0.5 \mathrm{~mm}$ was used for the cutting process. The work-piece measurements were taken using the digital Vanier Caliper and the statistical process control (SPC) software was used for the analysis of the data which were recorded on statistical data sheet.

\subsection{Methods}

The process capability study involve the generation of data from the shaft turning. The procedure for the study include Selection of the candidate material, evaluating the measurement system, preparing the control plan, analyzing data samples, estimating the process capability and establishing a plan for continuous turning process improvement.

The machine tests were carried out on the AJL180-325VS Gap Bed Lathes available at the Igbinedion University, Okada, Nigeria. The key parameters considered for purpose of viewing the machine tool capability are the cutting speed, the feed rate and the depth of cut. The straight turning operation shown schematically in Figure 1 was done for ninety (90) test piece at spindle speed of $300 \mathrm{rpm}-500 \mathrm{rpm}$, with feed rate $0.25-0.5$ $\mathrm{mm} / \mathrm{rev}$ at a depth of cut of $0.01 \mathrm{~mm}$ for nominal diameter of $40 \mathrm{~mm}$ with specification limit of $40 \mathrm{f} 7$ (tolerance of $0.025 \pm 0.050$ ). Roughly drilled hole are finished to specification H8 on each test piece to exact size by using a reamer which was mounted on the lathe tailstock. The cutting operation for the steel was performed at room temperature of $25^{\circ} \mathrm{C}$.

The Spindle speed, $N$, for the cutting process was obtained from Equation (1) [18].

$$
N=\frac{v \times 1000}{\pi D}
$$
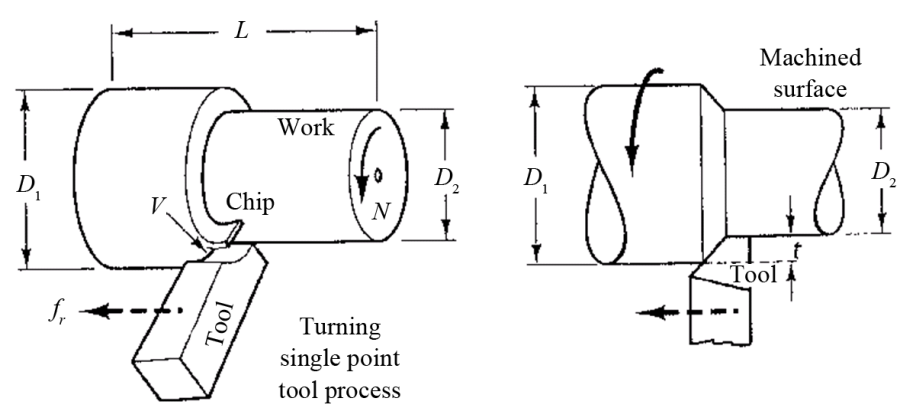

Figure 1. Turning single point tool process. 
where: $v$ is the cutting speed measured " $m / \mathrm{min}$ " and $D$ is the work-piece diameter measured in "mm". Moving range of two successive observations were used to determine the variability employed in deriving the control limits for the process. The variability of the process was measured in terms of the distribution of the absolute value of the difference of every two of the successive observations. The control limit were obtained from Equations (2)-(8)

$$
\bar{x}=\frac{\sum_{j=1}^{n} x_{j}}{n}
$$

where $\bar{x}$ the process mean, $j$ is the number of observation ranging $n$ observation, and $n$ is the subgroup size.

$$
\begin{array}{r}
\text { Moving range : } R=\sum_{j=1}^{n}\left|x_{i}-x_{j-1}\right| \\
\text { Average moving range : } \bar{R}=\frac{\sum_{j=1}^{n}\left|x_{i}-x_{j-1}\right|}{N} \\
\text { Upper Control Limit, UCL }=\overline{\bar{x}}+A_{2} \bar{R} \text { for x-bar chart } \\
\text { Lower Control Limit, LCL }=\overline{\bar{x}}-A_{2} \bar{R} \text { for x bar chart } \\
\text { Upper Control Limit, UCL }=D_{4} \bar{R} \text { for R-bar chart } \\
\text { Lower Control Limit, LCL }=D_{3} \bar{R} \text { for R bar chart }
\end{array}
$$

where $A_{2}, D_{3}, D_{4}$ are control chart constants which depends upon the size of the subgroup of the data.

The process capability indices, process average, and the standard deviation were obtained from the process data assuming that the data is normally distributed. The capability indices are obtained from the following expressions [4]

$$
\begin{gathered}
C_{p}=\frac{U C L-L C L}{6 \sigma} \\
C_{p k}=\min \left[\frac{U C L-\overline{\bar{x}}}{3 \sigma}, \frac{\overline{\bar{x}}-L C L}{3 \sigma}\right]
\end{gathered}
$$

where $C_{p}$ is the process capability for two-sided specification limit, irrespective of process center, $C_{p k}$ is the process capability for two-sided specification limits accounting for process centering and $\sigma$ is the standard deviation. The statistical process control (SPC) technique was used to assure that the process remains stable. The output of the turning process was compared with the specification limit using the capability indices.

\section{Results}

Table 1 shows the data obtained for three attempt of the turning process at various speed and feed rate of the operation.

Figure 2 shows the control chart for the machining operation. The Process Control Chart shows that the data points fell within the control limits. The moving range chart also indicates that all the data points are within the control limits indicating that the process is in statistical control and hence is under control and stable. Consequent upon this premise, the process capability evaluated by the use of capability indices via the SPC software is shown in Figure 2(b).

For the subgroup size of $n=3$, the control chart constants are obtained as, $A_{2}=1.023, D_{3}=0, D_{4}=2.574, d_{2}=$ 1.693, [19].

The control limit are thus obtained as shown in Table 2.

The process capability indices were obtained for the process data as $C_{p}=0.58$ and $C_{p k}=0.58$. This implied that the process is placed exactly at the center of the specification limits. And since $C_{p}<1$ the process is considered not adequate. The machine capability for industrial application is therefore not adequate and the process 
Table 1. Influence of cutting speed and feed rate on the machining tolerance limit of the center lathe.

\begin{tabular}{|c|c|c|c|c|c|c|}
\hline \multirow{2}{*}{ Sub-group/No. } & \multirow{2}{*}{$\begin{array}{l}\text { Speed } \\
\text { (rpm) }\end{array}$} & \multirow{2}{*}{$\begin{array}{c}\text { Feed/rev. } \\
(\mathrm{mm})\end{array}$} & \multicolumn{3}{|c|}{ Shaft diameter (mm) } & \multirow{2}{*}{$\begin{array}{r}\text { Ave. dia } \\
(\mathbf{m m})\end{array}$} \\
\hline & & & Attempt 1 & Attempt 2 & Attempt 3 & \\
\hline 1 & 300 & 0.25 & 39.960 & 39.965 & 39.960 & 39.962 \\
\hline 2 & 400 & 0.30 & 39.965 & 39.960 & 39.965 & 39.963 \\
\hline 3 & 500 & 0.50 & 39.965 & 39.965 & 39.965 & 39.965 \\
\hline 4 & 300 & 0.25 & 39.955 & 39.955 & 39.955 & 39.955 \\
\hline 5 & 400 & 0.30 & 39.960 & 39.960 & 39.960 & 39.960 \\
\hline 6 & 500 & 0.50 & 39.965 & 39.965 & 39.955 & 39.962 \\
\hline 7 & 300 & 0.25 & 39.955 & 39.955 & 39.955 & 39.955 \\
\hline 8 & 400 & 0.30 & 39.965 & 39.965 & 39.965 & 39.965 \\
\hline 9 & 500 & 0.50 & 39.960 & 39.955 & 39.960 & 39.958 \\
\hline 10 & 300 & 0.25 & 39.960 & 39.965 & 39.960 & 39.962 \\
\hline 11 & 400 & 0.30 & 39.955 & 39.965 & 39.960 & 39.960 \\
\hline 12 & 500 & 0.50 & 39.960 & 39.965 & 39.955 & 39.960 \\
\hline 13 & 300 & 0.25 & 39.965 & 39.955 & 39.955 & 39.958 \\
\hline 14 & 400 & 0.30 & 39.960 & 39.960 & 39.960 & 39.960 \\
\hline 15 & 500 & 0.50 & 39.960 & 39.960 & 39.965 & 39.962 \\
\hline 16 & 300 & 0.25 & 39.960 & 39.965 & 39.960 & 39.962 \\
\hline 17 & 400 & 0.30 & 39.965 & 39.960 & 39.955 & 39.960 \\
\hline 18 & 500 & 0.50 & 39.960 & 39.950 & 39.955 & 39.955 \\
\hline 19 & 300 & 0.25 & 39.955 & 39.960 & 39.960 & 39.958 \\
\hline 20 & 400 & 0.30 & 39.960 & 39.960 & 39.965 & 39.962 \\
\hline 21 & 500 & 0.50 & 39.960 & 39.965 & 39.965 & 39.963 \\
\hline 22 & 300 & 0.25 & 39.955 & 39.955 & 39.960 & 39.957 \\
\hline 23 & 400 & 0.30 & 39.965 & 39.955 & 39.965 & 39.962 \\
\hline 24 & 500 & 0.50 & 39.960 & 39.960 & 39.955 & 39.958 \\
\hline 25 & 300 & 0.25 & 39.960 & 39.965 & 39.965 & 39.963 \\
\hline 26 & 400 & 0.30 & 39.955 & 39.960 & 39.965 & 39.960 \\
\hline 27 & 500 & 0.50 & 39.960 & 39.965 & 39.960 & 39.962 \\
\hline 28 & 300 & 0.25 & 39.965 & 39.955 & 39.965 & 39.962 \\
\hline 29 & 400 & 0.30 & 39.965 & 39.960 & 39.955 & 39.960 \\
\hline 30 & 500 & 0.50 & 39.960 & 39.965 & 39.965 & 39.963 \\
\hline
\end{tabular}

Table 2. Control limit values or turned shaft data.

\begin{tabular}{ccccc} 
& & \multicolumn{2}{c}{ Control limits } & Std. dev. \\
\cline { 3 - 5 } & Center line & UCL & 39.966 & 39.955 \\
x bar chart & 39.96 & 0.015 & 0 & 0.003 \\
\hline
\end{tabular}




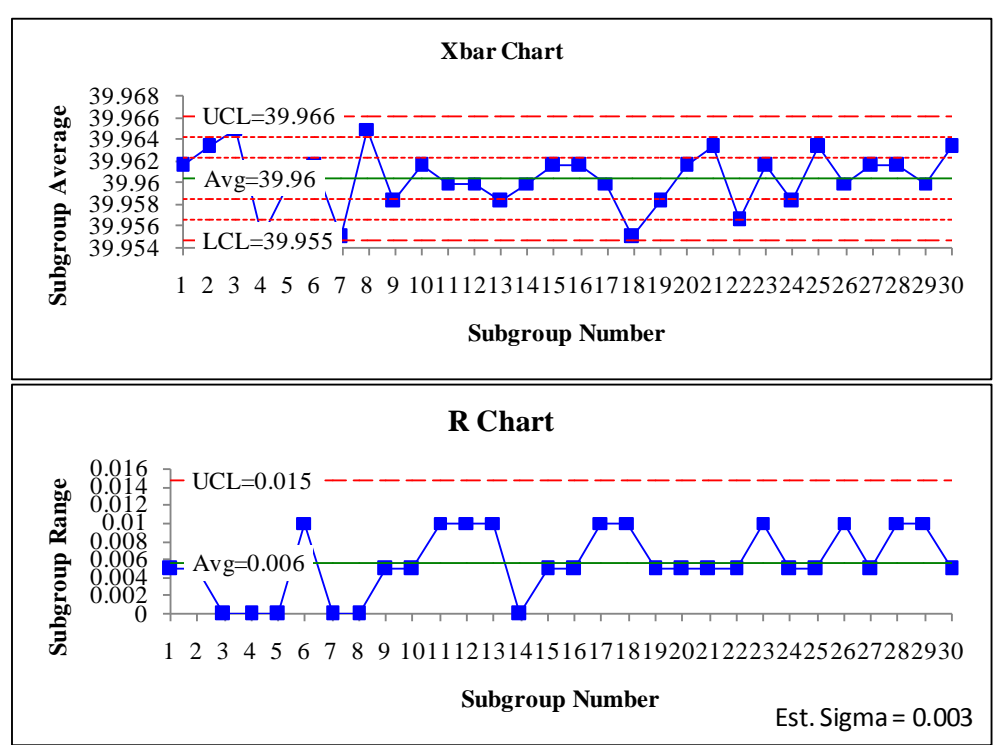

(a)

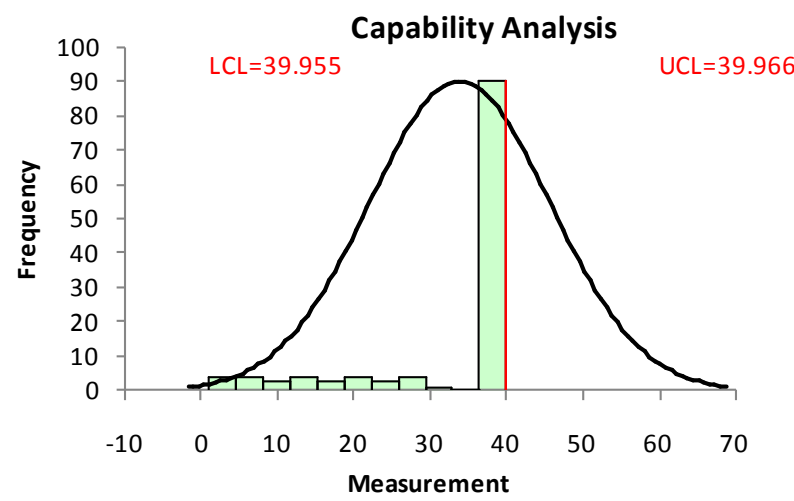

(b)

Figure 2. (a) Turning process control chart; (b) Process capability plot for the shaft turning process.

centering is also considered inadequate. In this circumstance, the $C_{p k}$ index is used to interpret the capability of the process. It therefore could be deduced that the process at varying feed rate and spindle speed is not capable of producing the quality required for the specified shaft. The machine settings are therefore not favorable and the process need be revisited to take the mean back towards the center.

\section{Conclusion}

The result of analysis of the data collected indicates that, the process is not capable of consistently bringing out shafts with diameter falling well within the customer's expectation, even though it remained in statistical control. Also, the process is not acceptable. The process owner cannot claim that the customer will not experience difficulty in the use of products which translate into losses. The reliability of such product resulting from the process cannot therefore be guaranteed.

\section{References}

[1] Sharma, G.V.S.S. and Rao, P.S. (2013) Process Capability Improvement of an Engine Connecting Rod Machining Process. Journal of Industrial Engineering, 9, 1-9. http://dx.doi.org/10.1186/2251-712x-9-37

[2] Wanare, S.P. and Gudadhe, M.V. (2013) Performance Analysis of Vertical Machining Center through Process Capability. International Journal of Innivations in Engineering and Technology, 2, 198-207. 
[3] Archenti, A. (2011) A Computational Framework for Control of Machining System Capability. Ph.D. Thesis of KTH Royal Institute of Technology, 97 p. https://www.diva-portal.org/smash/get/diva2:458645

[4] Rajvanchi, P.K. and Belokar, R.M. (2012) Improving the Process Capability of a Boring Operation by the Application of Statistical Techniques. International Journal of Scientific \& Engineering Research, 3, 1-6. www.ijser.org/viewPaperDetail.aspx?I014630

[5] Shreehah, T.A.A. (2010) Extending the Technological Capability of Turning Operation. International Journal of Engineering, Science and Technology, 2, 192-201. www.ijest-ng.com/ijest-ng-vol2-no1-pp192-201 http://dx.doi.org/10.4314/ijest.v2i1.59112

[6] Shinde, J.H. and Katikah, R.S. (2012) Importance of Process Capability and Process Performance Indices in Machine Tool. International Journal of Research in Engineering \& Applied Sciences, 2, 1211-1217. http://www.euroasiapub.org

[7] Kane, V.E. (1986) Process Capability Indices. Journal of Quality Technology, 18, 41-52. http://science.kennesaw.edu/ vkane/LSSInfo/KaneJQT

[8] Kahraman, F., Esme, U., Kulekci, M.K. and Kazancoglu, Y. (2012) Process Capability Analysis in Machining for Quality Improvement in Turning Operations. Material Testing, 54, 120-125. http://dx.doi.org/10.3139/120.110306

[9] Mottonen, M., Belt, P., Harkonen, J., Haapasalo, H. and Kess, P. (2008) Manufacturing Process Capability and Specification Limits. The Open Industrial and Manufacturing Engineering Journal, 1, 29-36. http://dx.doi.org/10.2174/1874152500801010029

[10] Senussi, G.H. (2007) Interaction Effect of Feed Rate and Cutting Speed in CNC-Turning on Chip Micro-Hardness of 304-Austenitic Stainless Steel. International Journal of Mechanical, Aerospace, Industrial, Mechatronic and Manufacturing Engineering, 1, 159-164. http://waset.org/publications/4706

[11] Thakur, D.G., Ramamoorthy, B. and Vijayaraghavan, L. (2010) Effect of High Speed Cutting Parameters on the Surface Characteristics of Superalloy Inconel718. Proceedings of the World Congress on Engineering, Vol. III, London, 30 June-2 July 2010. www.iaeng.org/publication/WCE2010/WCE2010_pp2108-2111

[12] Patil, M. and Patil, R.J. (2014) Study Effect of HSS Single Point Cutting Tool Nose Radius on Cutting Edge Strength and Tool Wear in Machining of EN9. International Journal of Science and Research, 3, 2563-2567. www.ijsr.net/archive/v3i12/U1VCMTQxMDcw

[13] Ojolo, S.J. and Ogunkomaiya, O. (2014) A Study of Effects of Machining Parameters on Tool Life. International Journal of Materials Science and Applications, 3, 183-199. http://dx.doi.org/10.11648/j.ijmsa.20140305.19

[14] Gokkaya, H. and Taskesen, A. (2008) The Effects of Cutting Speed and Feed Rate on Bue-Bul Formation, Cutting Forces and Surface Roughness When Machining Aa6351 (T6) Alloy. Strojniškivestnik—Journal of Mechanical Engineering, 54, 521-530. www.sv-jme.eu/scripts/download.php?file=/data/upload

[15] Selvaraj, D.P. and Chandramohan, P. (2010) Influence of Cutting Speed, Feed Rate and Bulk Texture on the Surface Finish of Nitrogen Alloyed Duplex Stainless Steels during Dry Turning. Engineering, 2, 453-460. http://dx.doi.org/10.4236/eng.2010.26059

[16] Khidhir, B.A. and Mohamed, B. (2010) Study of Cutting Speed on Surface Roughness and Chip Formation When Machining Nickel-Based Alloy. Journal of Mechanical Science and Technology, 24, 1053-1059. http://dx.doi.org/10.1007/s12206-010-0319-2

[17] Mears, L., Roth, J.T., Djurdjanovic, D., Yang, X. and Kurfess, T. (2009) Quality and Inspection of Machining Operations: CMM Integration to the Machine Tool. Journal of Manufacturing Science and Engineering, 131, 051006. http://dx.doi.org/10.1115/1.3184085

[18] Abdullah, A.B., Chia, L.Y. and Samad, Z. (2008) The Effect of Feed Rate and Cutting Speed to Surface Roughness. Asian Journal of Scientific Research, 1, 12-21. http://dx.doi.org/10.3923/ajsr.2008.12.21

[19] Joglehar, A.M. (2003) Statistical Method for Six Sigma. John-Wiley \& Sons, Inc. http://dx.doi.org/10.1002/0471721212 